\title{
Cultural Paradigms Of Age Discrimination And Unearned Privileges
}

Bahaudin G. Mujtaba, (E-mail: mujtaba@nova.edu), Nova Southeastern University Rose Marie Hinds, (E-mail: rosemarie.hinds@scotiabank.com), Nova Southeastern University Cuneyt Oskal, (E-mail: coskal@huizenga.nova.edu), Nova Southeastern University

\begin{abstract}
Discrimination cases and lawsuits are causing anxiety for many employers, managers and employees in the United States and are driving many good employees to courts or other organizations. One of the greatest fears of company officials and individual managers is the likelihood of either being sued for something that they have done intentionally or unintentionally, or for something that they should have considered doing but did not. One form of discrimination that has become widespread deals with age. Age discrimination in the workplace impacts people of all sizes, races, colors, religions, and ethnicities. It is no secret that age-related lawsuits proliferated during the last few years' recession and more recently age related claims have been on the rise as some of the layoffs seem to have been targeting older workers. Juries often side with aggrieved employees, even if the evidence is flimsy. Because of these trends, companies and their managers are realizing the need to protect their firms by periodically reviewing workforce diversity and proactively analyzing their work environment for latent signs of discrimination.

A cultural perspective of aging is discussed in the enclosed document along with the societal norms and perceptions of aging from the perspective of people in Afghanistan, Turkey, Jamaica, and the United States. Also, the concept of "unearned privilege" is discussed as it applies to age in different cultures. The focus of this material is discrimination based on age in order to create awareness and reduce the negative impact of stereotypes associated with "older workers." It is imperative that older workers are kept in the American workforce as long as possible, as there will be a shortage of skilled labor as early as 2005, if older workers continue to retire early.
\end{abstract}

\section{CULTURAL PERSPECTIVES ON AGING AND OLDER INDIVIDUALS}

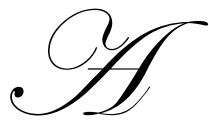

ging is viewed differently in different cultures depending on the stereotypes associated with becoming older. Such mindsets and paradigms can be seen in how societies respond to people of different ages, their customs, their norms, and opportunities provided to them. For example, the countries of Afghanistan and Turkey are not experiencing challenges in regard to age discrimination in the same manner as seen in the United States or in Jamaica. As such, a brief review of age discrimination from the various cultural perspectives seems appropriate.

An "older worker," according to the laws in the United States, is a worker that is 40 years of age or older. Unfortunately, there have been many firms that have shown patterns of discriminating against "older workers" in the American work environment. When such discrimination becomes an "unseen" part of the culture, it can hinder the organization's morale, productivity and may possibly cause legal problems for the firm. Organizations that have gotten themselves into such "slumps" of discriminating based on age must get themselves out of it by creating an organizational culture that values and respects long-term employment commitment and experience which tend to be a corollary of normal aging. As Johnny Bench, Hall of Fame Baseball Player, once said, "Slumps are like a soft bed; they're easy to get into and hard to get out of." Creating an effective organizational culture that avoids age discrimination requires long-term commitment and resources since there are no panaceas. Organizational leaders and managers must be concerned about age discrimination since an increasingly larger percentage of the workforce 
will come from the older population as baby boomers continue to age. As can be seen in Table 1, the baby boomers were born around 1946-1964 and make about 80 million individuals in the United States (Mujtaba, 2004). They grew up in suburbs, had educational opportunities above their parents, saw lots of consumer products hit the marketplace (calculators, appliances) and the television had a significant impact on their views of the world regarding equal opportunity and other human rights. Many members of this generation served in the military throughout the United States and around the globe. They enjoy perks that allow them to have more free time like errand-running service, car washes, food service, etc. The preferred learning environment of the Boomers is interactive and team activities. What is also interesting is that all of the baby boomers are now considered "older workers" since the last of them just became 40 year of age in 2004. However, they do not like being discriminated against because of their "older worker" status and many of them want to continue working even after the retirement age.

Table 1 - Various Generations in the United States

\begin{tabular}{|l|c|c|l|}
\hline $\begin{array}{c}\text { Generation } \\
\text { Category }\end{array}$ & Birth Years & $\begin{array}{c}\text { Population in } \\
\text { the USA }\end{array}$ & \multicolumn{1}{|c|}{ Common Characteristic } \\
\hline Traditionalists & 1900 s-1945 & 75 million & Stability and security \\
\hline Baby Boomers & $1946-1964$ & 80 million & Teamwork and human rights \\
\hline Generation X & $1965-1976$ & 46 million & Empowerment and social responsibility \\
\hline Generation Y & $1977-1994$ & 70 million & Technology and personal growth \\
\hline Cyberspace Gen. & $1995-$ Present & 20 million & Globalization and internet \\
\hline Total & & 290 million & \\
\hline
\end{tabular}

According to the United States Census Bureau and the Administration on Aging, the number of Americans who are 65 years of age or older has increased by a factor of 12 since the early 1900s (see Table 2: Aging Americans and the Workforce Statistics). The presence of more "older workers" being active in the workforce presents many challenges and opportunities for organizations. The challenges are stereotypes and age discrimination that are widespread in the American workforce. Organizations must effectively transcend such challenges and proactively take advantage of the experienced workforce as they attempt to be globally competitive. There are many proactive firms such as Publix, based in Lakeland, Florida which employed about 130,000 employees in 2003. Publix should be congratulated for their efforts to reduce and/or eliminate age discrimination in their workplace. As a matter-offact, Publix leaders and executives need to also be congratulated for their recent national award as one of the country's Top Employers of older workers - which was presented to them in September (2002) in Washington D.C. through the Experience Works Prime Time Awards Program. Of-course, there are many other such proactive organizations that value employee loyalty and experience, which eventually either reduces age discrimination in the workplace or, in ideal scenarios, eliminates it.

Table 2: Aging Americans and the Workforce Statistics

\begin{tabular}{|l|l|}
\hline Year & Americans 65 Years of Age or Older \\
\hline 1900 & 3 million (4\%) older workers. \\
\hline 2000 & 35 million (13\%) older workers. \\
\hline 2011 & First baby boomers will turn 65 years of age! \\
\hline 2030 & American 65 years of age or older are estimated to be at 70 million people (20\%) \\
\hline
\end{tabular}

As this document was being finalized in 2003 and early 2004, the author(s) interacted with at least ten colleagues in the information technology industry, who were current in their professions, to understand their perceptions about the presence of age discrimination in technology fields. The following is a summary from a few of their thoughts on age discrimination in the technology driven sector. 
- $\quad$ "I do agree that age discrimination is definitely out there, but it is also highly dependent on the type of job and industry. In certain jobs, I think it is foolish to put an extremely young person in a job that requires significant experience, something an elder candidate may possess. I am in my mid-20s and can say without a bias towards the younger generation, that I still feel experience is a big factor in success and that experience is usually found in the elder generation. I am simply trying to do an analysis to the reasons behind age discrimination. For example, we have seen the dot.com era boom and bust. In many of these dotcoms, the executives were young and in my opinion, lacked the experience to truly lead these companies to success. However, as always, there are exceptions, and certain young people have created highly successful businesses. This implies that the young generation with new ideas is capable of leading a company. In contrast, I thought of how many young executives are leading the Fortune 500 companies, and not surprisingly, most of the big blue chip companies are led by elder and more experienced leaders. Obviously, this is also proof that the model of having experience on the side is crucial to success. Here, the younger generation may claim age discrimination for the upper management jobs."

- $\quad$ "Overall, age discrimination mainly depends on the type of job and who qualifies for it in terms of updated information and capability in the field. I don't claim to have seen the world, but in my line of work, I have been fortunate enough to not have witnessed age discrimination. In fact, as our team focuses on the mainframe servers, many of the younger members rely on the tutelage and guidance of the senior members who have a much deeper understanding of the mainframe systems. And in the past, when I've seen layoffs, it usually ends up being the younger ones, as the senior ones are much too valuable because of their astounding knowledge."

- $\quad$ "From experience, I have observed that due to the technologies involved and adopted by the newer generation, the dotcoms were likely to hire employees with a similar educational background. Usually, other younger folks shared these similar backgrounds. Similarly, I have usually seen executives promoted in big companies after years of proven experience. I have had certain experiences where I have witnessed age discrimination in both aspects, positive and negative. And, I have tried to analyze the reasons behind this. We all know of the negative age discrimination; often this is due to unfair prejudices and stereotypes. However, one example that sticks to my mind is when I was at a training session with a coworker in his mid-late 50s. The training focused on all the new technology pertaining to e-business on the mainframe. A part of the training focused on the new development tools, and my coworker decided to mention in front of the manager that he wasn't too interested in learning the new technologies saying, "this stuff is too complicated, let the young people deal with it, and let me just do the traditional mainframe stuff." In our jobs, we are required to stay current with the new technology so we can consult to our customers. The manager took that statement as his inflexibility in a dynamic environment to contribute to the team. In the future, could this lead to a dismissal? Perhaps, but can he really claim age discrimination? In this case, the manager would be doing what he/she sees as the right thing for the team. In contrast, we have another team member, also in his mid-late 50s and only a year from retirement, who still demands training on the new technologies to improve and broaden his skills. Not only does he understand the mainframes better than us, he is very formidable in the newer technologies. In the past rounds of layoffs, he has survived where many of the younger employees have not. If all of a sudden, he was to be let go for a younger replacement, he may be qualified for an age discrimination lawsuit. But, knowing his skills, I doubt that will happen."

\section{Perceptions of Aging in the United States}

The United States of America (USA) has a diverse population of about 280 million people. A culture's perspective on aging in the USA can be seen from their comedy. The comedian George Carlin, uses aging in his appearances and states:

If you're less than 10 years old, you're so excited about aging that you think in fractions. "How old are you?" "I'm four and a half!" You're never thirty-six and a half. You're four and a half, going on five! That's the key. You get into your teens, now they can't hold you back. You jump to the next number, or even a few ahead. "How old are you?" "I'm gonna be 16!" You could be 13, but hey, you're gonna be 16! And then the greatest day of your life... you become 21. Even the words sound like a ceremony . . YOU BECOME 21. . YESSSS!!! But then you turn 30. Oooohh, what happened there? Makes you sound like bad milk. He TURNED, we had to throw him out. There's no 
fun now, you're just a sour-dumpling. What's wrong? What's changed? You BECOME 21, you TURN 30, then you're PUSHING 40. Whoa! Put on the brakes, it's all slipping away. Before you know it, you REACH 50 . . and your dreams are gone. But wait!!! You MAKE it to 60. You didn't think you would! So you BECOME 21, TURN 30, PUSH 40, REACH 50 and MAKE it to 60. You've built up so much speed that you HIT 70! After that it's a day-byday thing; you HIT Wednesday! You get into your 80s and every day is a complete cycle; you HIT lunch; you TURN 4:30; you REACH bedtime. And it doesn't end there. Into the 90s, you start going backwards; "I was JUST 92." Then a strange thing happens. If you make it over 100, you become a little kid again. "I'm 100 and a half!" May you all make it to a healthy 100 and a half!

Such negative views, expressed by the American comedians, associated with aging are common in the United States. They are representative of how the American society feels about aging and as such youthfulness is valued and "older age" is not as is the case in Turkey and Afghanistan. These mindsets are causing an increasing number of the aging baby boomers to constantly search for the "fountain of youth" when in reality there is no such panacea. Nonetheless, such societal views tend to impact the workplace since senior executives and managers that make hiring decisions do come from the society and they do not always check out such mindsets and stereotypes associated with aging at the door. This societal conditioning is like personal traveling luggage that accompanies a person from one airport to another airport and from one hotel to another and finally back home. Unlike one's luggage, stereotypes and biases do not become lost, at least not automatically. They must be consciously replaced by appropriate new "luggage" or "paradigms and mindsets."

The American culture seems to be obsessed with youth (Kelly, 2003) as can be seen from the increasing number of cosmetic surgeries while members of media are fully capitalizing on such obsessions in their ads and selling efforts. Such youth-mindedness is also accompanied by a negative perception of aging in the society, which is inclusive of the workplace. While many of the Asian and Middle Eastern cultures value and respect older individuals (both in their personal and professional lives), Americans view aging from a negative perspective as if it was a bad thing. These negative perceptions tend to convey the message that older workers are not able to keep up with new technology or new ways of doing things because they are not open minded. Besides the perception of not being open minded, older workers in the American society are seen as: "deadwood, incompetent, closed minded, untrainable, and less productive" (Kelly, 2003). Of-course, these are stereotypes and myths that are not factual and individuals disproving these myths are ubiquitous in today's workplace. Nonetheless, such views tend to put older individuals at a huge disadvantage as they attempt to compete in the job market with their younger counterparts. On the other hand, young Americans tend to have this "unearned privilege" or "unearned advantage" that comes to them at a cost to "older workers." The term "unearned privilege" and "unearned advantage" will be explored toward the end of the document.

\section{Discrimination Facts and Documentaries from the American Workplace}

Thinking back to your life experiences you will recall that we all, at some point in time, have undergone experiences when we were treated differently because of our physical differences and other such characteristics. While we all have experienced unfair treatment at one time or another we will see how some individuals in society may be exposed to this type of treatment on a more consistent basis. In fact, some individuals may experience such unfair treatment on a daily basis. This unfair treatment is called daily indignities - negative things that individuals do or say to or about one another on a continuous basis, because of their biases and perceived differences. This is one definition of "daily indignities" that one of the authors has used in diversity workshops for managers and executives. Also, the National Multi-Cultural Institute (NMCI), a Washington-based non-profit institution, has used similar definitions to begin discussions on subtle and blatant forms of discrimination in our society.

These daily indignities are demonstrated in many different forms and age discrimination is one of them. Several documentaries have been created that show these various forms of daily indignities or discrimination. These documentaries depict various forms of discrimination in actual work and daily life situations. Typically, two people, called "testers" are used. They are equal in all characteristics except the chosen discriminatory one, like age, appearance, skin color or gender. Usually the testers are sent to a location to check on public response to a diversity characteristic in real life settings such as applying for a job, buying a car or making a major purchase, using the 
services of an employment agency, renting an apartment, and shopping in a store. An example of such a documentary that focuses on age discrimination is titled "Age and Attitude" which was aired several times to national and international audiences at ABC's "Prime Time" in the 1990s.

The Age and Attitude documentary focused on discrimination based on age and attitude. In this documentary, a single male tester assumes two identities. He is "made up" to be a 27 -year old candidate (named Joseph) and a 53-year old candidate (named Michael) seeking employment. Michael, the older tester, possesses slightly better job qualifications than Joseph. They enter into identical employment opportunity situations with the following results. The 27-year old tester consistently received various employment offers even though the 53 year old tester possessed better qualifications. In one instance, the older tester is told during the interview, "this is a young boy's game!" When the employers were confronted and asked to explain these results, they could not offer any logical explanation as to why the younger tester was consistently offered the employment opportunity over the older tester.

Some of these decisions may be attributed to the myth that older workers are more sickly, not as committed, and will not stay with the company as long. Once again, facts prove these myths are all false! Based on the authors' combined forty years of corporate and management experience throughout Afghanistan, Jamaica, Turkey, and the United States of America, associates over the age of 40 tend to be much more experienced, stable, and often times more dependable than younger associates who are in their early twenties. They also tend to be mature, more customer savvy, loyal, honest, quality focused, relationship oriented, and skilled in positive interpersonal communication.

Data shows that age discrimination is such a part of American society that it is even more difficult to detect than either racial or gender discrimination. It is also a fact that older workers (over 40) usually require 64\% more time to obtain employment than their younger counterparts. Equal Employment Opportunity Commission (EEOC, 2003), which administers ADEA, provided relevant statistics (see Table 3: Age Discrimination Charges in America) that show a rise in age discrimination cases during the past few years.

It should also be mentioned that discrimination did not occur every time in the aforementioned documentary, some of the discrimination might have been unintentional, and it is possible that some of the discrimination that occurred was not because of the particular characteristic being tested. Nonetheless, such forms of age discrimination are prevalent in the United States and possibly widespread in the workplace. A pattern of such discrimination could cost the company major losses in lawsuits.

Table 3: Age Discrimination Charges in America

\begin{tabular}{|c|c|c|}
\hline Year & $\begin{array}{c}\text { Charges of Age Discrimination } \\
\text { Filed with EEOC }\end{array}$ & $\begin{array}{c}\text { Percentage of Total EEOC } \\
\text { Charges }\end{array}$ \\
\hline 1992 & 19,573 & $27 \%$ \\
\hline 1999 & 14,141 & $18 \%$ \\
\hline 2000 & 16,008 & $20 \%$ \\
\hline 2001 & 17,405 & $21.5 \%$ \\
\hline 2002 & 19,921 & $23.6 \%$ \\
\hline
\end{tabular}

\section{Perceptions of Aging in Jamaica}

Jamaica is one of the many islands of the Caribbean with strong historical and cultural ties to both West Africa and Great Britain. The population, almost three million, is a diverse blend of many different races with the majority being of African descent. The Jamaicans culture, similar to others, is expressed through local stories, songs, dances, the use herbs and bush medicine, local beliefs, the preparation of indigenous food s and through religious practices. Jamaicans perform folk songs and dance mainly during festivals and independence celebrations. During celebrations it is customary to wear their nation costumes, which is called the Bandana. Jamaica's folk culture began 
mainly in the rural and mountainous villages. The main contributors to Jamaican culture are the groups of people who made Jamaica their home. These are the African, the English, The Spaniards, and the Indians. Jamaica, an island country, is the third largest island of the Greater Antilles of the West Indies and is situated south of Cuba. With its picturesque mountains and beautiful beaches, the island is known for its serene natural surroundings and is a popular tourist destination for many individuals throughout the world. Jamaica became a British colony in 1670 . During the 18th century, planters began importing African slaves to work on the sugar plantations. Today the island's culture and customs blend its British and African roots. Jamaica gained its independence from Britain in 1962 and maintains a strong two-party political system. The island is named after the Native American word Xaymaca, meaning "isle of springs."

Over the centuries, there has been a variety of marriages of both different races and cultures, inevitably resulting in a fair tolerance of diversity. However, there are issues of discrimination arising out of what has been loosely called the "classis model" or more formally, "class discrimination." This, of course, is a legacy of the Island's history of slavery and colonialism, where the slave owners and colonizers were the "haves" and the working class members were the "have-nots." During slavery, and later colonization, Jamaicans were identified not only based on skin color, but also based on wealth and status.

The advent of the information age, aided by the Worldwide Web and Cable Television, has exposed Jamaicans to various other cultures. One could assume that with the majority of Jamaicans being of African descent, as well as the British influence on their culture, Jamaicans would have very distinct ideas on social issues such as age discrimination. And, ostensibly they do, but in reality Jamaicans seem to take their cues from the outside world the "first world." In this regard, no single culture has impacted the Jamaican people as much as that of North America. Jamaican attitudes tend to mirror American norms, beliefs and values more as the years progress.

As has been the case in North America, there has been a trend towards age discrimination in Jamaica. While there are no specific laws governing this issue locally, and accordingly, very little public reflection on the matter, an informal review of several typical Jamaican companies reveals that persons between the ages of forty five (45) and sixty five (65) are more likely to be "downsized" or laid off, and less likely to be hired. There is also a noticeable trend towards encouraging early retirement. As a matter-of-fact, a colleague at NSU stated that, during early 2003, her brother was forced into early retirement from his long-term employment in Jamaica because he was 55 years of age and he was boldly told it was because of his age.

Over the past decade many Jamaican organizations have engaged in some form of restructuring, leading to changes in their workforce. Quite often, restructuring that involves automation or reengineering results in redundancies of supposedly "less qualified persons" and the recruitment of more "technologically savvy" personnel. These new recruits somehow mostly seem to fall within the ambit of the age group defined as "Generation X", and more recently, "Generation Y."

Discussions with various local (Jamaican) Managers involved in the recruitment process revealed an interesting trend. While most Managers are willing to admit to a preference for hiring from the Generation X pool of knowledge workers, hardly any are willing to call that preference "age discrimination." When prodded for a classification of this type of behavior, managers cite other factors as their motivation. One Manager indicated that he assesses recruits for "a bias towards particular mindsets." He indicated that it has been his experience that job seekers from the Baby Boomer Generation are more likely to suffer from paradigm paralysis and are less likely to be open to new perspectives, especially from younger colleagues. Accordingly, he said, he would be willing to admit to mindset discrimination, not age discrimination.

Another factor cited was the knowledge level of the younger workforce compared with that of the older generation. Although the older recruits inevitably have more experience but this is not always a requirement for the job. Recruitment Managers indicate that they would prefer to hire younger, "brighter" workers who are open-minded and trainable than older workers who are "set in their ways." It is believed that the younger generations are more teachable because they pursue higher levels of academic learning which better prepares them for experiential learning. Supposedly, they are also more in tune with and open to new technologies compared to their counterparts. 
Conversely, Jamaica being a third-world country with only one major university during the 1960s to 1980s, only a small percentage of the local Baby Boomers were afforded tertiary level education. Therefore, it is perceived that they have less appreciation of the need for continuous learning, a feature of the new "learning organization."

Managers also cited a third "honorable and justified" reason for their preference of younger workers: this being the "economic reality of diminishing returns." It is believed that older workers cost more to maintain and are less energetic than younger workers. One Manager actually cited his views based on "personal experience" that "a person's performance tends to peak after a number of years (roughly eight years) and after that the rule of diminishing returns sets in." The authors consider these views expressed in support of this preference for a younger workforce to be very disturbing, especially in light of the fact that many of these views are not supported by factual research but merely on perception. It is also disturbing that Managers do not see their behavior as being discriminatory.

Jamaica, like many other third world countries, is just beginning to view human resources management as a multi-dimensional field and, as such, many sensitive issues including age discrimination are not routinely addressed. However, as a member of The International Labour Organization (ILO) and also based on Jamaican's habit of mirroring American norms, Jamaicans will no doubt become sensitized to, and take appropriate actions against such issues as age discrimination in the workplace in the foreseeable future.

The western influence on the Jamaican workforce tends to put older individuals at a disadvantage as they attempt to compete in the job market with their younger counterparts who are viewed to be technologically savvy and up-to-date by many of the current managers. As such, young Jamaican professionals have certain "unearned privileges" or "unearned advantages" that come to them simply because they are younger and such privileges often come at a direct cost to "older workers."

\section{Perceptions of Aging in Afghanistan}

Afghans, who recently had their first historic democratic elections in October 2004, have traditionally been conditioned to respect authority, age and their elders. It is noted that the twenty fives years of war in the past few decades have brought about some exceptions to this tradition. However, the authors would like to focus on the general tradition and culture of the Afghans. Their conditioning of respecting authority and their elders comes from their origin and history. The word "Afghan" represents all people born in Afghanistan and those who were official citizens of the country as agreed upon by the ten day deliberation of the Loya Jirgah, the General Assembly, in the 1964 constitution. Symbolically, the word Afghan stands for love, courage, devotion, dignity, and the desire to make sacrifices for one's country and people. It further symbolized endurance, patriotism, dedication to the Afghan land and customs, and the freedom to soar in the beautiful mountains and deserts that are considered to be their ancestor's protected backyards. Afghans are known to be people of honor, great hospitality and are committed to being masters of their own destiny. They are also known to have a high level of respect for their elders both in the community and in the workforce. Age is culturally seen as a sign of experience and wisdom. Elders are usually consulted for major decisions and retired elders tend to serve as coaches, mentors and chiefs in the community. The honor of Afghan people for their elders is legendary and they are usually willing to fight for causes deemed important by their elders in the community. Also, their hospitality toward elders knows no bounds as they would go out of their way to please senior citizens, especially those who are their parents or family members but strangers would receive good hospitality as well. In return for good hospitality, most elders would offer a prayer or their blessing which is all that one may seek for his/her service.

Afghanistan has a population of approximately 28 million individuals and half of them are females. The Afghan community and workforce are as diverse, if not more, as the population of Miami or Orlando of Florida. So, they too could and have suffered from not effectively managing their diversity. According to the Orlando Sentinel in the early 1990s, there were individuals from over 52 different ethnicities living and working in the Central Florida area of Orlando, Florida. The city of Miami has had over 1.3 million Spanish-speaking individuals from very diverse cultures. If these two cities that are filled with individuals of different ages, ethnicities, nationalities, languages, genders, preferences, and religious backgrounds can learn to work effectively, then the diverse 
population of Afghanistan's workforce can certainly work synergistically as well. While, people in Afghanistan have overcome many challenges associated with various forms of discrimination due to different ethnicities but they do not have the same stereotypes about "older workers" as seen or perceived in the American workplace. The corporations in both Miami and Orlando tend to have many training and development sessions for their employees so they can be aware of discrimination issues based on race or age. Training and development in the area of diversity management tends to be offered by most managers to assist them to treat each current and prospective employee with respect and dignity regardless of their age or nationality. Managing diversity is about enabling each member of the department to perform up to or beyond his or her potential. It is about creating a competitive advantage for the organization through the human resource asset (regardless of their age), which happens to be the most important asset for many organizations! While the Afghan culture could benefit from diversity-related workshops, they do not need any training on age discrimination in Afghanistan since people are conditioned to respect age and their elders. Bahaudin, one of the authors, was born/raised in Afghanistan and stayed there for seventeen years. He was brought up to respect his elders at home, in the community, at school, and in the society regardless of whether he agreed with their thoughts or not.

It was through diversity management workshops that Bahaudin learned about many of the stereotypes associated with age and other forms of discrimination in the American culture. Bahaudin learned that media has influenced us very much and it can give us the wrong image about individuals from various cultures. It was through socialization in the American workforce and through the media that Bahaudin either heard, read, or saw images, stereotypes and depictions of:

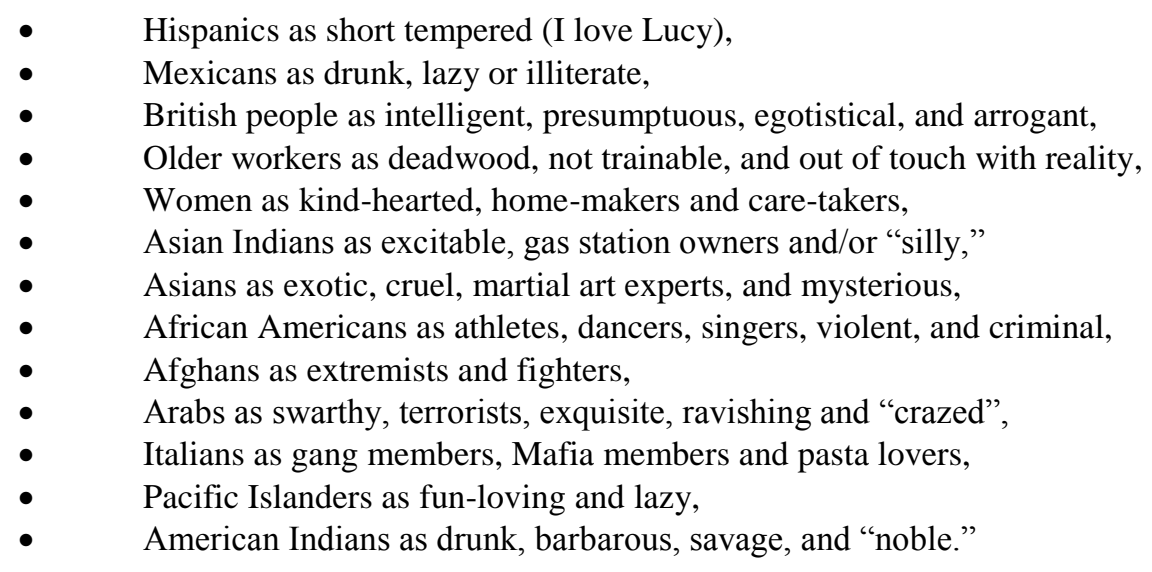

Such stereotypes, much of which are false, are widespread in the American workforce and some other parts of the world due to the influence of media. Such perceptions can also impact one's behavior toward others which in return impacts employee turnover and can eventually bring about costly lawsuits. However, when it comes to age, most Afghans who live in the United States still tend to be guided by their Afghan heritage and respect elders at home and in the workforce because they are seen as mentors and coaches with much wisdom due to their extra years on earth.

One can say that societal conditioning during one's upbringing and socialization in the Afghan society tends to offer older professionals advantages due to their seniority in age as they compete in the job market despite the fact that their younger counterparts may at times be better educated, technologically more savvy and perhaps more up-to-date in their professions. As such, older Afghan professionals have certain "privileges" or "advantages" that come to them simply because they are older even though some younger individuals might be better qualified.

\section{Age discrimination in Turkey}

Turkey is a Middle Eastern country with a population of 70 million people. About $90 \%$ of the total population is considered moderate Muslims, mostly struggling to become economically stable society with morals that come from a religious, but still laicized background. It has been a secular country since 1923, when the founder 
of the Turkish republic called Ataturk established the democratic and secular Turkey. About half of the population is in the range of 20-40 years of age. As such, Turkey may be the one of the largest countries that has a high percentage of young population in the Middle East, maybe in Europe as well. Nevertheless, the government has not come up with a feasible long-term strategy to benefit from this generation. There are two kinds of corporations and businesses in Turkey; Private companies that belong to individuals and families; and government-owned and government-managed companies.

The difference in performances of those two sectors is quite remarkable. Because of the fact that the private sector is purely profit-oriented, the private sector tends to be more open to new ideas from the young/dynamic employees. Eventually, this openness to new ideas and innovation makes the private sector more competitive and up-to-date. The reason for the Turkish government to be involved with business life was mainly because of the fact that when the Turkish Republic was established almost 80 years ago after the collapse of the biggest empire in the history called the Ottoman Empire, almost none of the Turkish people and Turkish families were financially able to invest in or establish a corporation. That is why the new government of the new-born Turkish Republic decided to be the frontier of a new industry.

Ataturk's original idea was to establish corporations that are necessary for survival in the industries that play an important role in a country's future then sell them out to interested individuals and families that want to run them. Since then, it has been a continuous project for the government to leave the management of governmentowned corporations to the private sector. Presently, Turkish government mainly runs the corporations that deal with water management, power plant management, heavy metal industry (steel, etc.), and so on.

The challenge for an older employee in the private sector is tougher than that of the government-owned ones'. Moreover, the perception on the private sector is that the government-owned companies suffer from the lack of dynamism and innovation.

The common sense of the Turkish culture is that the older a person the more maturely he or she will react to crisis, not only in businesses, but also in one's personal life. Moreover, there are plenty of common local sayings that emphasize the importance of being older and experienced. For example; one's words do not count unless one is able to grow facial hair (the sign of getting old).

In comparison to the Western countries, despite the fact that the percentage of young generation is higher in Turkey, the average ages of employees in the corporations tend to range close to 40's. In other words, they are still remarkably higher in Turkey than that of other countries in Europe, and the young generation still suffers from not being able to find enough opportunities to start their professional business life.

In terms of job security, Turkey is a country, in which mostly the experience of an employee that comes with age is superior to the advantage of youth. The common perception is that unless the company is going bankrupt or one commits a shameful crime, most companies tend to keep the employees until they retire. In the governmentowned sector, one has the opportunity to continue working even after the retirement age. On the negative side, so much security for an employee sometimes causes lack of motivation for productivity and a decrease in performance that usually lead to loss of profit.

In Turkey, almost all government-owned companies suffer from the fact that there are too many employees working for a few available positions. This eventually affects the overall performance and causes Turkish government plenty of problems like millions of dollars in deficit. In addition to that, most of the young generation who are getting ready to start building their professional careers end up losing hope in finding a decent position to start with after spending a remarkable time searching for a job. Because of the security of the existing jobs for current employees, mostly the older employees, the younger ones do not tend to have enough opportunity to prove themselves as young and dynamic members of the workforce. Even if they do get an opportunity to start working, they usually find themselves in the middle of conflicts or disputes with older and more experienced employees in order to apply their young and fresh ideas to their organizations. This is also considered to be one of the reasons for the migration of young Turkish workforce to other countries such as the United States, Canada, Australia, and 
Europe where the youth seem to be more appreciated. Research conducted by different universities in Turkey, such as the Middle Eastern Technical University, show that the young workforce want to explore the possibilities in other countries that prefer employing young individuals.

As implied above sometimes a country's cultural preferences and conditioning for older workers can cause difficulty for the younger generation. The young generation in Turkey is trying to find alternative solutions to the existing challenge (age discrimination toward younger employees) so they can become a dominant force into the business world and in the government sector. Unfortunately, because of the fact that bringing a lawsuit is almost impossible against the Turkish government and its integrated system in professional business life, the young generation continues exploring possible solutions to be able to step into the professional business life by traveling to other countries.

So, similar to the Afghan society, one can say that societal conditioning and socialization in Turkey tends to offer older professionals certain advantages due to their seniority in age despite the fact that their younger counterparts may at times be better qualified and perhaps more up-to-date in their professions. As such, older Turkish professionals have certain "privileges" or "advantages" that come to them simply because they are older even though many younger individuals might be better qualified.

\section{UNEARNED ADVANTAGES ASSOCIATED WITH AGE AND CULTURAL ALLIES}

With regard to "unearned advantage," young people are also affected in ways that are very subtle. The term often used to refer to this concept is "unearned privilege." Unearned privileges are advantages given to some individuals and withheld from others, without regard to their efforts or abilities, because of their perceived difference. Every individual falls into a group/club based on his or her age, gender, body size, skin color, culture, ethnicity, race and other characteristics. If your group has large numbers or power and prestige, you fit right in the middle of the curve, right in the "norm." Those people in the norm have some privileges that those outside the norm do not have. In real life terms, they get a little boost, a leg up, a "bennie," or a little extra. This does not mean that life is handed to them on a silver platter and they do not work hard. Despite the fact that they work hard for what they get, in addition to that, they may still get a little boost. The paradox is that they do not even know it. When told of it, they might even disbelieve it. When you are in the "norm" you think that is the way it is for everybody. It is not! There is the old Afghan parable about the king and his son, which illustrates this point. The king and his six year-old son were watching the poor workers of the country that are on strike due to low wages pass through the King's castle and yell bad things about the King because of the inflation and hunger. The son asked, "Dad, why are they on strike and yelling such bad things about you?" The King replied, "They are hungry and need bread so they can eat and survive." The son replied by confirming his understanding and making a suggestion to solve the problem by saying "well, if they are hungry and don't have any bread, why don't they just eat cake and cookies?" While eating cake and cookies was the norm for the king's son it is a colossal luxury for a person who cannot even afford to buy a piece of dry bread so that s/he can survive another day. The moral of this story is that when you are in the "norm" you think that is the way it is for everybody. However, in reality it may not be so regardless of how much one may want things to be that way.

The existence of unearned privilege for younger workers can lead to increased tension, stress, and frustration because it usually comes at a cost to someone else which in this case is older workers. Sometimes, the society automatically affords you an unearned privilege because you fall in the norm (for a specific characteristic such as gender or body size) and sometimes you may have to work harder because the society is not structured toward your needs. Let us focus on something other than age to demonstrate unearned privilege. For example, society structures everything for right-handed persons, which means that left-handed individuals have to function in a right-handed world. The school desks, manufacturing machines, scissors, doorknobs, golf clubs, and other necessities of life are usually built for right-handed individuals. Therefore, Mustafa who was born left-handed must adjust to sit in a right-handed desk at school, work in a factory that has machines which requires that use of right hand for maximum productivity, and has to buy special golf clubs for extra cost that are specifically built for the left hand. Nadeem, on the other hand, was right-handed and loves the chairs in the school; the machines in the factory are just right for him and he always achieves maximum productivity without any extra efforts; and, he can play golf 
with almost any golf clubs that are available in any shop. Since Nadeem is right-handed and almost everything is built for right-handed individuals, we can say that he has certain privileges (just because he falls in the norm) that are not necessarily afforded to Mustafa. Many people can think of their own characteristics that have earned certain privileges without any effort or work on their part. For example, being a male can have certain advantages as well as certain disadvantages. Also, being short can have many advantages and at other times many disadvantages. In the case of age in the American society, it is an advantage until one gets to be an "older worker." During the young age, people enjoy "unearned advantages/privileges" and tend to lose them as they become older. People in Afghanistan, Turkey and many other Asian countries tend to automatically get certain privileges because of their seniority in age. For example, characteristics such as wisdom, experience, intelligence, maturity, leadership, and many others are often associated with "older workers" or "elders" but not necessarily with younger workers or individuals. Unearned Privilege is a subject that requires deep and introspective thought but one can conclude that those who have unearned privileges are seldom aware that they have it. Those who do not have the privilege are very much aware that they do not have it. Unearned privileges are very subtle in society and such advantages can create tension, stress, and frustration in diverse environments. When people are aware of such advantages, they can personally assist in making sure another person is not impacted negatively in their department. So, refuse accepting privileges that you have done nothing to earn (that is if you are ever offered a job simply because you are young when a more deserving person who happens to be an "older worker" did not get it because of his/her age) and become a "cultural" ally for those who are not in the norm. Sometimes when you think about the magnitude of the challenges that exist in the society, you may feel that you cannot make a difference. However, we as individuals can make a difference by becoming cultural allies. Companies should expect their managers to be allies in the workplace in order to eliminate age discrimination. As you become more culturally competent with regard to age discrimination, you will find more and more opportunities to be a cultural ally. Cultural ally refers to those individuals who intervene or interrupt in order to stop mistreatment or injustice from occurring to other individuals. Such mistreatments can be as subtle as age discrimination toward "older workers" that cannot be seen but is very widespread in the American workplace. So, one solution for eliminating age discrimination is for everyone to personally become a cultural ally, which will eventually replace the stereotypes with the truth about "older workers."

It may not always be obvious to some people how important our older workers are to the economy and businesses, but older workers contribute immensely to the success of not only the United States, but to other countries of the world. In a national survey, older workers were found to possess the following qualities: functioning well in crisis; possessing basic skills in writing, reading, and arithmetic; loyal; solid performers; and good interpersonal skills (Harvey \& Allard, 2002). Older workers have various talents that are vital to many businesses in the world today, and those skills are not just restricted to multinational or huge corporations but they also apply to smaller and specialized organizations. For example, a company by the name of Vita Needle, in Needham, Massachusetts, manufactures stainless steel tubing and needles have a reputation of employing mainly older workers with an average age of 35. This company hires older workers because there utilizing older workers is part of their core competency. There are certain qualities that the older workers possess that fit into the goals and policies of the company. When the President of the company, Fred Hartman, was interviewed by Tom Brokaw, NBC Nightly New, he said that the primary reason he continuously recruits older workers was because the assembly of their metal components was done by hand, and older employees were "extremely conscientious employees, loyal, dedicated, aware of quality requirements, and very reliable" (Harvey \& Allard, 2002). Another example of a company that has benefited immensely from managing older employees is the Aerospace Corporation in El Segundo, California. They have a "Retirement Transition Program" which makes available to its highly skilled employees four different options namely, pre-retirement leaves of absence, part-time status working towards retirement, post retirement employment based on consultancy, and post retirement in the form casual employment.

\section{RETAINING AND ATTRACTING OLDER WORKERS}

It is critical that employers exercise extreme caution within their corporate culture to minimize any inferences of older workers being mistreated. 'How can this happen' one might ask? It actually starts at the top. Corporate culture is shaped at the top of the corporate ladder by the senior executives and managers who determine how human resources are to be utilized. If key executives are entrenched in a culture that views younger people as being more successful and aggressive and older people as being more complacent, then those beliefs will create a 
negative climate that will permeate throughout their organization, thereby, causing subordinates to buy into the same type of behavior. Given this, senior executives and managers, as well as the entire workforce within organizations should make every effort to ensure their corporate culture is a positive one, avoiding any instances that may make older workers feel uncomfortable.

In addition to the aforementioned measures, there are common sense and good judgment solutions that must be considered as well.

- $\quad$ First, avoid both blatant and subtle forms of discrimination as well as inappropriate comments.

- $\quad$ Second, maintain candid one-on-one conversations with older workers regarding how they perceive the situation.

- Third, managers should ensure training opportunities are available to everyone and encourage older workers to keep their skills current.

- $\quad$ Finally, avoid unexpected lawsuits. This might be the most common category of "everyday management," managers must remain cognizant of common cultural and socioeconomic misunderstandings and important developments regarding age discrimination.

Research shows that about sixty-eight percent of workers between the ages of 50 and 70 plan to work during their retirement or never retire at all. It's a business decision. With a workers shortage in the next decade or so, American employers need to attract skilled older workers and retain current employees as they age. Other countries, including developing countries may find themselves in the same position as more jobs transfer to them due to cheaper labor. Among the benefits offered by employers to retain and attract experienced workers are:

- $\quad$ Financial Services. Some companies offer some sort of retirement plan, but the best ones provide workshops, seminars, and counseling. Example: First Tennessee National Corp., a financial services firm in Memphis, assigns advisers to help employees devise retirement plans, and retirees have their own dedicated financial specialist.

- Health Benefits. Most of the employers offer not only basis benefits-prescription drugs and health, vision, and dental care-but long-term care insurance and short-and-long term disability insurance. Some even offer wellness programs. Example: Roche Inc., a New Jersey-based pharmaceutical company, offers a program that includes free health screenings and customized fitness programs.

- $\quad$ Training Opportunities. This includes everything from skill development to career counseling. Example: The Massachusetts Institute of Technology offers career training to all employees and courses specifically for workers over 50 .

- $\quad$ Mentoring. Ideally it works two ways: 1) Experienced employees help train younger workers and 2) Older workers return to the company and receive a mentor to help retrain them. Example: At the University of Phoenix and at Baptist Health, experienced employees can receive payments for mentoring new employees.

- $\quad$ Flexible Schedules. Forget the punch clock: 28.8 percent of American workers now have a flexible schedule, nearly twice as many as 10 years ago. Example: SSM Health Care in St. Louis, Missouri, offers time off for dependent care, and spouses of retirees can take summers off to travel.

- $\quad$ Phased Retirement. Rather than quit cold turkey, many employees prefer to ease into retirement. Example: Bon Secours Richmond Health Systems in Richmond, Virginia, lets workers shift to part-time or on-call status-and they have to work only 16 hours per two-week pay period to retain benefits.

- Welcome Back Policies. Some companies allow retirees to return to work after they've left the job. Example: The MITRE Corporation, a not-for-profit systems engineering and information technology company based in Massachusetts and Virginia, offers Reserves at the Ready, a program that allows retirees to be on call for part-time work.

In many cases, a company's attitude toward older workers has a lot to do with the industry. Age bias is especially pronounced in youth-oriented sectors like advertising, e-business and technology, and securities. The entertainment industry is notorious for its youth obsession (a California judge recently dismissed an age suit filed by older writers against the networks and movie studios). When there are so many technology driven firms banking on quick profits filled with predominantly younger workers, you tend to find more age bias. There is a perception that 
younger managers often have a difficult time supervising older workers. One young manager at an interview with Dianne Saywer of $\mathrm{ABC}$ News said managing older workers is like managing one's parent which is not an easy task.

\section{SUMMARY}

Age discrimination tends to exist more often during bad economic times and often appears quite rational. Many employers feel as though they have solid economic reasons for not wanting to hire and train employees who will soon be retiring. Furthermore, others rationalize that people do "slip" with age. Some researchers have stated that reasoning skills may decline with age, and the decrement is greatest in what psychologists call "fluid intelligence." While some of these myths/opinions might have been based on few factual occurrences, they are not always representative of an individual's ability to successfully complete a task, regardless of his/her age. For example, older professionals are one of the desired categories of employees in India, Afghanistan, Turkey, as well as in many other Asian and Middle Eastern countries. Some of the reasons why older workers are among the sought after workers in these collectivistic-oriented cultures may include the cultural respect associated with age, job stability of experienced workers and consistency in the quality of work performed by older professionals. Companies have recognized that older workers value stability and quality in their work, so they are taking advantage of it. There is a mutual benefit here because the companies offer older workers the stability that they desire and in return the older workers utilize their expertise and stability to the benefit of the organization.

"We are now targeting hiring alternate profiles...the industry is customer service-driven and older people are sensitive to customer needs" wrote Khan (2003). It becomes clearer that some companies are tapping into the advantages of having highly skilled older workers within their organizations. Another example of a company that has utilized older employers for quite a while and is still exploring better ways of managing older employees is McDonald's. Michael O'Shaughnessy, employee relations director, McDonald's Australia, said fast food chains target older employees. He went on to say that a program aiming at recruiting more "older workers" was in the works (Comtex, 2003).

In summary, as more and more companies downsize, merge and are bought out because of economic reasons, layoffs and cutbacks are inevitable. This concerns all managers because with these cutbacks, one cannot help but to think that the employment of older workers will be impacted significantly. The general feeling is that many more employers are going to focus on a more youthful workforce, rather than one that is mature and more experienced because of the stereotypes, myths and costs associated with the "older workers." It has been witnessed that individuals have lost their jobs over the past several years because of layoffs, and have always wondered why certain employees with similar characteristics (such as being over the age of 40) were selected rather than others. Many of these people have had a number of years invested in their organizations, but were dismissed regardless of their seniority. It has also been witnessed that younger workers have consistently been brought into organizations and this consistency of the age characteristic makes one wonder "why?" For these reasons, among many others, managers should consciously decide to increase their knowledge in human resources and age discrimination issues in order to become more aware of the laws governing unfair employment practices, in hopes of making a positive difference in the lives of experienced, honest, loyal, able, knowledgeable, and willing workers.

\section{REFERENCES}

1. Administration on Aging (2001). "Department of Health and Human Services". [Online]. Retreived November 13, 2003 from: http://www.aoa.dhhs.gov/

2. Bennett-Alexander, D. (1998). "Employment Law for Business", $2^{\text {nd }}$ ed. Blacklick, OH: Irwin/McGrawHill. As cited in Regulation of Discrimination in Employment, p. 326.

3. Bucher, Richard D. (2000). Diversity Consciousness: Opening Our Minds To People, Cultures And Opportunities. Upper Saddle River, NJ: Prentice-Hall.

4. Cabrillo College (2001). "Older Workers in the Labor Market: A Report from the Congressional Research Service”. [Online]. Available: http://www.cabrillo.cc.ca.us/

5. Clark, K., (2003). "Judgment Day". Money \& Business. U.S.News.com. Retrieved on January 13, 2003 from URL: http://www.usnews.com/usnews/biztech/articles/030113/13performancehtm 
6. Comtex (2003). "McDonalds Targets Older Workers”. Retrieved October 30, 2003, from Infotrac.

7. Cornell Law School (2001). "Age Discrimination in Employment”. As cited in United States Code; Title 29-Labor: Chapter 14. [Online]. Available: http://www.law.cornell.edu/.

8. Critchley, R. K. (2002). Rewired, Rehired, or Retired? A Global Guide for the Experienced Worker. San Francisco: Jossey-Bass/Pfeiffer.

9. "Federal Laws Prohibiting Job Discrimination Questions and Answers." The U.S. Equal Employment Opportunity Commission. Retreived on October 04, 2003 from: http://www.eeoc.gov/facts/qanda.html

10. Fyock, C. D. \& Dorton, A. M. (1994). UnRetirement: A Career Guide for the Retired ...the Soon-to-beRetired...the Never-Want-to-be-Retired. New York: Amacom.

11. Harvard Business Review (2001). HBR on Managing Diversity. Harvard Business School Publications.

12. Harvey, Carol P. and Allard, M. June (2002). Understanding and Managing Diversity: Readings Cases and Exercises. Second ed., Prentice Hall.

13. Kelly, E. P., (2003). "Ethical Perspectives on Layoffs of Highly Compensated Workers and Age Discrimination in Employment." The Journal of Applied Management and Entrepreneurship. Val. 8, No. 3. Pages 84-97.

14. Khan, S.Y. (2003) "Desperately seeking older employees". Retrieved October 1, 2003, from Infotrac.

15. Konovsky, M., \& Haynie, B.G. (2001). "Performance criteria in RIF and their impact on age Discrimination lawsuits". Employee Rights Quarterly. Autumn. Retrieved October 1, 2003 from Infotrac.

16. Maurer, T.J., \& Rafuse, N.E. (2001). "Learning, not litigating: Managing employee development and avoiding claims of age discrimination." Academy Management Executive. Retrieved September 12, 2003, from AgeLine.

17. Microsoft Encarta (1993-2000). "Age Discrimination" [Computer Software]. Microsoft Encarta Encyclopedia 2000: Microsoft Corporation.

18. Mujtaba, B. and Thomas, G., (2004). "Leading and Managing Disparate Generations of Employees to Deliver Value in the Twenty First Century's Cross-Cultural Learning Organizations." Proceedings of the International College Teaching Methods \& Styles Conference.

19. Mujtaba, B.; Hinds, R. M..; \& Oskal, C. (2004). "Cultural Perspectives of Age Discrimination and Unearned Privileges Associated with Age." Applied Business Research Conference (ABR) Proceedings.

20. Mujtaba, B.; Richardson, W.; and Blount, P. (2003). "Age Discrimination and Means of Avoiding It in the Workplace!" Presented \& published in SAM International Conference Proceedings on "Trust, responsibility, and business."

21. Nobile, R.J. (1998). Essential Facts: Employment (Age Discrimination). Warren, Gorham \& Lamont: Boston, Massachusetts, Section 6.4, pp6-12 - 6-13.

22. Quirk, J. (1993). "A Brief Overview of the Age Discrimination in Employment Act A (ADEA)." Reviewed June 1999. Available online: http://my.shrm.org/whitepapers/documents agediscrimination.

23. Steinhauser, S. (1998). "Age Bias: Is Your Corporate Culture in Need of an Overhaul?" Available online: http://my.shrm.org/hrmagazine/articles/default.asp htm.

24. Thompson, R.W. (January 2000). "Tight Labor Market Seen as boon for Older Execs." HR Magazine. P.10.

25. U.S. Bureau of the Census, 2002. "Population : Older Americans 2000 : Key Indicators of Well-Being." Retreived 4/3/2003 from : http://www.agingstats.gov/chartbook2002/population.htmal

26. Uchitelle, L. (2003). "As jobs shrink, older workers thrive." International Herald Tribune, September10. Retrieved October 1, 2003, from Infotrac.

27. Walsh, L. (2003). "Older, wiser and still enjoying the rat race." Europe Intelligence Wire. July 5. Retrieved October 1, 2003, from Infotrac.

28. Yeatts, D.E., Folts, W., \& Knapp, J. (2000). "Older workers' adaptation to a changing workplace: Employment issues for the 21st century." Retrieved October 1, 2003, from Biomedical Reference Collection: Comprehensive. 